\title{
El animal, el fármaco y la autodeconstrucción del libro
}

\author{
The Animal, the Pharmakon and the Self-Deconstruction of the Book
}

\author{
Por: Tenner, Pedro * \\ UNSAM-UBA-CONICET \\ Buenos Aires, Argentina \\ pedro_tenner@hotmail.com
}

Fecha de recepción: 15/06/2021

Fecha de aprobación: 28/11/2021

DOI: https://doi.org/10.30972/nvt.1725762

\section{Resumen}

En el presente artículo nos proponemos estudiar la relación entre las nociones del libro y del animal en la obra de Derrida. Nos remitiremos en primer lugar a "La farmacia de Platón", pues creemos que esta relación se comprende bajo la lógica del doble y el desdoblamiento vinculada a la noción del fármaco. En segundo lugar, nos volveremos hacia La escritura y la diferencia y De la gramatología, donde mostraremos cómo la fármaco-lógica ya está operando al menos en un elemento crucial: la estructura constitutiva y auto-deconstructiva del libro, que está acechado por su doble animal.

Palabras clave: Derrida, animal, libro, deconstrucción, fármaco

\begin{abstract}
In this paper we will attempt to study the link between the notions of the Book and the Animal in Derrida's work. In the first place we will refer to "Plato's Pharmacy", for we believe that this link is best understood under the logic of the double and the unfolding associated with the notion of pharmakon. Secondly, we will turn towards Writing and Difference and Of Grammatology, where we will show how this pharmaco-logic is already at work at least in one

\footnotetext{
* Licenciado en Filosofía. Becario del CONICET con el tema "Biopoder e impoder animal desde la perspectivas de Jacques Derrida".
} 
El animal, el fármaco y la autodeconstrucción del libro

crucial element: the constitutive and self-deconstructive structure of the Book, which is haunted by its animal double.

Keywords: Derrida, animal, book, deconstruction, pharmakon

\section{Cómo citar este artículo:}

APA: Tenner, P. (2021). El animal, el fármaco y la autodeconstrucción del libro. Nuevo Itinerario, 17 (2), 159-177. Recuperado de: (agregar dirección web)

\section{Introducción}

En el presente trabajo nos proponemos estudiar la relación, esbozada en los escritos tempranos de Derrida, entre las nociones del libro y del animal. Para ello, nos remitiremos en primer lugar a "La farmacia de Platón", pues creemos que esta relación se comprende bajo la lógica del doble, el desdoblamiento y la duplicación que Derrida vincula a la noción de fármaco. En efecto, el fármaco abre el espacio intersticial de un juego de espejos y dobles: un lugar (o no lugar) donde lo mismo será ya siempre su propio contrario, y oscilará entre sí mismo y "sí otro". Veremos que Derrida vincula explícitamente este desdoblamiento con figuras animales.

En segundo lugar, nos volveremos hacia La escritura y la diferencia y De la gramatología, textos anteriores en los que, si bien el significante "fármaco" no aparece de forma prominente, mostraremos cómo la fármaco-lógica ya está operando al menos en un elemento crucial: la estructura constitutiva y auto-deconstructiva del libro. Puntualmente en La escritura y la diferencia, Derrida encontrará un carácter animal del significante, que horadará desde dentro el libro haciéndolo posible e imposible a la vez. Así, el libro, espacio eminente de la presencia y de la mirada humana, se verá duplicado por su otro: el animal. Esta auto-deconstrucción y/o autoinmunidad en el seno del libro o de lo humano repite avant la lettre la estructura del fármaco que Derrida presentaría posteriormente.

El análisis nos permitirá, finalmente, aislar la operación o el mecanismo bajo el que se debe emprender una deconstrucción de lo humano: una escritura 


\section{Pedro Tenner}

deconstructiva no debería introducir la muerte en la estructura que pretende desmontar, sino que deberá aprovechar la muerte ya inherente a esa estructura, en este caso bajo la forma del animal. El libro como espacio eminente de lo humano se deconstruye a partir de una repetición que deja entrever su animalidad ya latente.

\section{El zoofármaco}

En su ensayo "La farmacia de Platón", Derrida se concentra, a lo largo de su lectura del Fedro, en la noción de fármaco. Según el filósofo francés, las propiedades ambiguas del fármaco, que le dan potestad a una vez sobre la vida y la muerte, permiten entrever un espacio de indecidibilidad "anterior" a las oposiciones tradicionales de la metafísica. ${ }^{1}$ El fármaco será entonces ambivalente por "constituir el medio en que se oponen los opuestos, el movimiento y el juego que los relacionan mutuamente, los revierte y los hace pasar uno al otro" (Derrida, 1997:191). Como tal, ofrece la reserva inagotable de la que la filosofía, la metafísica o la dialéctica pueden extraer sus filosofemas y ponerlos en juego en las series tradicionales de oposiciones; sin embargo, también constituye un intersticio de inestabilidad y temblor que amenaza la transparencia y la pureza de esas mismas oposiciones. El fármaco hace entonces a una vez posible e imposible la filosofía como un pensamiento de lo verdadero en oposición a lo falso, el ser en oposición al no-ser, etc. Derrida (1997: 103) resume que el fármaco es aquello que "resiste a todo filosofema, excediéndolo indefinidamente como no-identidad, no-esencia, no-sustancia, y proporcionándole de esa manera la inagotable adversidad de su fondo y de su ausencia de fondo".

El filósofo francés enfatiza que el fármaco no remite a la mezcla de dos elementos previamente separados, claramente distintos uno del otro, sino "a lo mismo que no es lo idéntico, al elemento común, al medio de toda disociación posible" (Derrida, 1997:191). Se trata aquí del espacio donde lo mismo no es idéntico porque ya difiere de sí, ya introduce una escisión consigo mismo y está en pugna consigo mismo,

\footnotetext{
${ }^{1}$ Sobre el fármaco, el doble y la indecidibilidad, cf. Bass (1984).
} 
pues sin dejar de ser sí mismo ya es lo otro de sí mismo. ${ }^{2}$ De esa manera, esta diferencia de sí inscribe el fármaco en la problemática del doble. Rastreando la indistinción entre la repetición del significado y la repetición del significante (pues apenas una nada separa al significado del significante), ${ }^{3}$ Derrida (1997: 168) señala que la discriminación entre ambas repeticiones "se sutiliza hasta no separar ya, en última instancia, más que al mismo de sí, de su doble perfecto y casi indiscernible. Movimiento que se produce por entero en la estructura de ambigüedad y de reversibilidad del pharmakon".

Así, en el ámbito de la farmacología o fármaco-lógica todo está ya duplicado, todo es su propio otro. Lo mismo se separa de su otro apenas como la cara de una hoja de papel se separa de su anverso, y por ello no debe esperar que su muerte advenga desde fuera, sino que él mismo ya es su muerte; al constituirse, lo mismo se corroe a sí mismo y se imposibilita a sí mismo. Sumido entonces en este trasfondo del fármaco, en este fondo sin fondo, Derrida (1997: 256) dirá que "el ser-presente (on) en su verdad, en la presencia de su identidad y la identidad de su presencia se dobla desde que aparece, desde que se presenta. Aparece, en su esencia, como la posibilidad de su propia duplicación". Ahora bien, esta duplicación casi perfecta entre lo mismo y lo otro garantizará la total reversibilidad del fármaco. Derrida observa que, dada su diferencia consigo mismo y dado que incluye sus afueras, el fármaco es el único remedio/veneno posible contra sí mismo. ${ }^{4}$ Por ello dirá, por ejemplo, que Platón puede oponerse a la sofística utilizando argumentos sofísticos, u oponerse a la escritura "mala" proponiendo otra escritura "buena". Así, el fármaco demuestra una "complicidad profunda en la ruptura" consigo mismo (Derrida, 1997: 168). Sin embargo, Derrida

\footnotetext{
${ }^{2}$ Derrida refiere aquí a la diferencia entre lo mismo y lo idéntico que Heidegger desarrolla en Identidad y diferencia, donde lo mismo no es lo idéntico porque ya incluye en sí un movimiento diferencial y de auto-sublevación.

${ }^{3}$ Cf. De la gramatología: "la diferencia entre el significado y el significante no es nada" (Derrida, 1986: 31). Es interesante que Derrida observa un carácter autocontradictorio en esta proposición, que por lo tanto es en sí misma farmacológica: "Esta proposición transgresiva, no siendo estimada en un discurso previo, corre el riesgo de formular la regresión misma".

${ }^{4}$ Como ha señalado Lindberg, ya aquí se encuentra operando la lógica de la autoinmunidad que Derrida desarrollaría recién en Fe y saber. Para Lindberg (2016: 378), la autoinmunidad es un "mecanismo" inherente a un organismo "que convierte al organismo mismo en un pharmakon". Una posición semejante es la de Lippit (2000), como veremos más adelante. Es siguiendo a estos dos autores que, en este trabajo, propondremos la vinculación entre autoinmunidad y fármaco.
} 


\section{Pedro Tenner}

(1997: 190) resalta que "esta no-sustancia farmacéutica no se deja manejar con toda seguridad, ni en su ser, puesto que no lo tiene, ni en sus efectos, que pueden incesantemente virar de sentido". En el fondo farmacéutico, no es posible saber de qué lado se está, nunca puede determinarse si el fármaco nos está jugando en contra o a favor, pues estrictamente siempre está haciendo ambas cosas. Es el lugar donde crecen a una vez el peligro y la salvación. ${ }^{5}$

En este contexto, entonces, podemos hallar al menos dos referencias al animal y su relación con el fármaco. Una de ellas la encontramos siguiendo el ejemplo eminente de reversibilidad: la indistinción entre el logos y sus contrarios, a saber, el mito, la magia, la locura, etc. Así, estudiando aquellas concepciones del logos anteriores a la decisión platónica que intentó (y necesariamente fracasó) deslindar sólo una de sus caras, Derrida (1997: 174) concluye que "antes de ser dominado, domado por el kosmos y el orden de la verdad, el logos es un viviente salvaje, una animalidad ambigua". El fármaco-logos se vislumbra como un animal porque es salvaje y ambiguo, anterior a los cortes, las decisiones o las oposiciones civilizatorias y humanas de la filosofía.

Y es precisamente al hablar de los límites de lo humano que Derrida relaciona nuevamente el fármaco con lo animal. La segunda referencia se introduce en una nota durante una descripción del Sócrates platónico como un pharmakeus:

A la vez y/o alternativamente, el pharmakon socrático petrifica y despierta, anestesia y sensibiliza, tranquiliza y angustia. Sócrates es la mantarraya narcótica, pero también el animal con aguijón: recordemos la abeja del Fedón [...] Toda esta configuración de Sócrates compone, pues, un bestiario. ¿Es extraño que lo demoníaco se muestre en un bestiario? Es a partir de esa ambivalencia zoofarmacéutica y de esa otra analogía socrática como se determinan los límites del anthropos (Derrida, 1997: 179).

Resulta interesante que Derrida evoque la imagen del bestiario que, entre sus acepciones, incluye la de un género literario; pues así se adelanta el tema que abordaremos en la sección siguiente, a saber, la indecidibilidad entre el libro y el animal. De hecho, lo "demoníaco" que puntualmente el bestiario representa aquí

\footnotetext{
5 Hacemos referencia aquí -como creemos que hace tácitamente Derrida- a la famosa frase de Hölderlin que Heidegger repite frecuentemente.
} 
remite a la indecidibilidad e inestabilidad de la figura del daimon, tanto en sus apariciones en la mitología griega como en su implementación por la filosofía platónica. El bestiario, además, supone una multiplicidad de animales, una variedad de formas de vida o maneras de ser entre las que Sócrates puede oscilar, deslizándose sutilmente de una a otra. Lo animal empieza a designar así el intersticio, el "entre", el subjectil o el milieu fluido que se atisba "detrás" de las oposiciones estáticas de la filosofía, oposiciones que constituyen el ámbito de la transparencia humana. ${ }^{6}$ El logos socrático, campeón eminente de la racionalidad humana y de las formas eidéticas, apenas se distingue de la anti-sustancia amorfa del zoofármaco; está de hecho duplicado por ella y subsiste gracias a que puede adoptar su carácter fluido y revertirlo contra ella. Así, duplicado por lo animal e introduciéndolo, el ámbito del logos humano encuentra en lo zoofarmacéutico su condición de posibilidad, pero también de imposibilidad, pues nunca puede constituirse enteramente en sí mismo, sin ser ya su otro. Lo animal es su reserva inagotable y su perpetua amenaza. ${ }^{7}$ Como ha señalado Akira Mizuta Lippit (2000, 71), siguiendo a Derrida, "el ser animal fuerza a la humanidad a reconocer la finitud del mundo: es decir, los animales arrancan a la humanidad de la totalidad imaginada del mundo". ${ }^{8}$ El animal no deja de acechar a través de las grietas de un mundo humano que se finge total y cerrado sobre sí.

\footnotetext{
${ }^{6}$ Sobre el tema del "entre", el zwischen o el intersticio cf. Cragnolini (2002: 112), para quien se trata aquí del "médium" en que se mueven los pensamientos del perspectivismo nietzscheano o la deconstrucción derridiana, es decir, de un "modo de pensar que no busca seguridades últimas (puntos arquimédicos, puntos finales) sino que opera a partir de un continuo movimiento, que genera sentidos como modos de enfrentamiento con lo caótico, pero que recrea esos sentidos en una tarea continua de disgregación de los mismos (para que no se transformen en nuevas seguridades)".

${ }^{7}$ Así, ya aquí se hace posible entrever la idea, que Derrida hará explícita en El animal que luego estoy si(gui)endo, de que la filosofía ha sido el esfuerzo constantemente reanudado (por su fracaso inevitable) de trazar un umbral claro y estable entre lo humano y lo animal (cf. Derrida, 2008: 57-8). Es interesante considerar que, como límites del hombre, el animal se confunde (aunque no al punto de la identificación) con otros dos espacios de los que el hombre intenta diferenciarse: la máquina y lo divino. Derrida señalará (1989: 98) que lo divino es, precisamente, "la desaparición del hombre". Por otro lado, Lindberg (2016: 371) observa que hay en Derrida un tratamiento similar de la máquina y del animal: el autor francés "despliega una serie vasta y abierta de diferentes capacidades técnicas y dispositivos tecnológicos [...] de manera similar a cómo examina el singular plural l'animot en lugar del universal Animal". Como veremos más adelante, esta aproximación depende de que lo animal, lo maquínico y lo divino son espacios de impersonalidad a los que la mirada humana, siempre personal, no accede. ${ }^{8}$ Cf. también Cragnolini (2016a: 111), para quien "lo animal es una alter-ación en lo humano (una extrañeza, una otredad que desarma la mismidad y la propiedad de sí)."
} 


\section{Pedro Tenner}

\section{La animalidad ilegible de la letra}

Esta idea de una totalidad resquebrajada e imposibilitada por su propia conformación puede rastrearse en la manera en que Derrida describe la ambigüedad autoinmunitaria del libro que, como veremos, también está acechado por su doble animal. Así, en los textos anteriores a "La farmacia de Platón", encontramos una economía similar de las nociones del animal, lo amorfo y el doble, referidos allí al problema del libro y del hombre. En De la gramatología, Derrida ha demostrado que el libro, lugar privilegiado de la escritura metafísica occidental, no es accesorio al desarrollo de esa escritura, sino que la constituye esencialmente. ${ }^{9} \mathrm{Y}$ constituye, por lo tanto, al hombre como correlato necesario de la metafísica de la presencia (es decir, de la metafísica en general). ${ }^{10}$ En efecto, "la idea del libro es la idea de una totalidad, finita o infinita, del significante; esta totalidad del significante no puede ser lo que es, una totalidad, salvo si una totalidad del significado constituida le preexiste, vigila su inscripción y sus signos, y es independiente de ella en su idealidad" (Derrida, 1986: 25). La época del libro, como momento necesariamente humanista, buscará neutralizar el significante al imponerle una totalidad, un cierre, sea en el campo de la finitud o de una infinitud actual y positiva. Ese intento de "domar" el significante en la totalidad, o de resumir su huella, sólo será comprensible desde la concepción del significado como un ente ideal independiente y presente. La escritura eminentemente humana será la escritura fonética y lineal de la letra, o la literatura, es decir, la escritura que se extiende de margen a margen en el libro y que sólo "recubre" el significado ya existente.

Sin embargo, el esfuerzo filosófico de Derrida ha tendido desde sus comienzos a demostrar que el significado no existe de manera independiente antes de un

\footnotetext{
9 Adinolfi (2011: 409) ha resaltado esta manera derridiana de entender la relación entre la filosofía/metafísica y el libro: "no está en cuestión simplemente un objeto tipográfico, sino en cuanto es portador de una cierta idea o ideal, que como una suerte de focus imaginarius ha guiado el operar de la filosofía, su lógica". Adinolfi discute también la manera en que el texto de Derrida oscila entre el libro como Idea y el libro como objeto concreto, oscilación que nosotros pretendemos aprovechar, pues, como veremos, creemos que para Derrida el Libro como espacio cuasi-transcendental es apenas una apertura siempre ya suplantada por sus vicisitudes concretas y mundanas.

10 "El nombre del hombre es el nombre de ese ser que, a través de la historia de la metafísica o de la onto-teología, es decir, del conjunto de su historia, ha soñado con la presencia plena" (Derrida, 1989: 400).
} 
significante al que luego adviniera, sino que está siempre ya duplicado por el significante, y constituido por él. ${ }^{11}$ Así, el significado y su otro, su muerte o ausencia, están en una relación farmacológica en que cada uno es el doble del otro. Ello significa que, dentro del ámbito del libro, el significado no podrá existir antes de su inscripción en la letra, que entonces estará desdoblada en dos caras casi indistintas, apenas separadas: la humana del significado y la del significante, que tendrá un carácter animal. En efecto, en "Edmond Jabès y la cuestión del libro", Derrida (1989: 99) enfatizará que "hay una animalidad de la letra que toma las formas de su deseo, de su inquietud y de su soledad". Contra la idea de una letra inerte o fija, Derrida insiste en que la cara significante introduce una diseminación y una equivocidad constitutivas e inagotables: "la animalidad de la letra es la equivocidad primera e infinita del significante como Vida" (Derrida, 1989: 100). La constitución del significado depende del movimiento y la dislocación constantes introducidas con cada repetición del significante, en una errancia que Derrida describe bajo la forma de una vida animal inquieta e impulsada por el deseo de su propagación o procreación. La animalidad de la letra es propiamente la "sobrepotencia" (sur-puissance) de la que es capaz el significante, un poder de operar siempre un nuevo desplazamiento en el seno del significado, para constituirlo. De esa manera, el significado no es nunca fijo, asible o certero, pues la cara significante, su doble opaco e inevitable, siempre ya habrá inscrito en él el elemento de la equivocidad y la incertidumbre. Remover la "contaminación" animal no culminaría en la adquisición de un significado presente y estable, sino en la muerte de toda posibilidad de significación. Por ello, Derrida (1989: 100) insiste en que la animalidad no constituye aquí una metáfora entre otras, sino que es la metaforicidad misma como dislocación y différance, y como producción del lenguaje: "La animalidad de la letra [...] es sobre todo la metáfora misma, el origen del lenguaje como metáfora".

Además del deseo y la inquietud, Derrida enfatiza la soledad de la letra como parte de su carácter animal: "sería letra muerta fuera de la diferencia, y si rompiese la

\footnotetext{
${ }^{11}$ Además de la frase ya citada de De la gramatología, donde Derrida habla de la no diferencia entre significante y significado, cf. la Introducción al Origen de la geometría donde Derrida enfatiza el carácter constitutivo del signo escrito que Husserl ha descubierto.
} 


\section{Pedro Tenner}

soledad, si rompiese la interrupción, la distancia, el respeto" (Derrida, 1989: 99). La letra está viva en tanto que se respeta su soledad, la distancia y la interrupción que la separa del autor. La letra-animal se pierde de vista y un rastreo minucioso de su huella o su errancia la mataría. ${ }^{12}$ Así, ese movimiento de propagación, impulsado por el deseo y la inquietud procreadores, transcurre en un intersticio solitario y animal precisamente porque ocurre en los márgenes de la mirada humana, a pesar de que constituye esa misma mirada. Tiene lugar a espaldas del hombre, del sujeto humano soberano y, en apariencia, plenamente consciente de sí. La reproducción animal de la letra ocurre entre líneas, "más allá de la rigidez de las líneas" (Derrida, 1989: 99), en el espacio negativo e invisible entre renglón y renglón. Y porque la letra se reproduce en este intersticio animal, jamás es posible rastrear ni dirigir su desplazamiento. Aquí también queda la animalidad vinculada a un "entre", un milieu o un subjectil que constituye en tanto disloca aquello que constituye. La escritura literaria -espacio eminente del hombre-, está constituida por un movimiento animal que escapa al poder y al control humanos. Como resultado de este punto ciego, la soberanía del hombre se ve amenazada desde dentro. ${ }^{13}$

A primera vista, la letra parecería lo eminentemente legible porque muestra una cara que siempre está al alcance de la mirada humana; pero la transparencia literaria sólo existe desde que está duplicada por su otro opaco, desde que lleva "soldada" a sí una cara ilegible o un punto ciego: el intersticio solitario e inaccesible de la reproducción animal. Esta ilegibilidad animal pone en cuestión la transparencia

\footnotetext{
${ }^{12}$ Esta noción de un "texto a pérdida de vista" la retoma Derrida en "La doble sesión", ensayo de La diseminación (p. 307).

${ }^{13}$ Seguimos a Cragnolini (2016b) en este aspecto de la soberanía humana amenazada por un intersticio o subjectil animal. La autora ve en la escritura un espacio de lo impersonal, el "entre" de todo sujeto o ipse humano: "la escritura se patentiza como ese lugar de lo impersonal, en el que un quién que quiere erigirse continuamente por encima de la lengua [...] deviene algo diferente" (Cragnolini, 2016b: 195). El "quién" humano queda acechado por el "qué" del animal, pues el animal está siempre merodeando en el campo aparentemente humano del lenguaje. "El animal parece", señala Cragnolini (2016b: 198), "subordinado en el discurso, pero éste no sería posible sin él; ni voz ni escritura que plasmaran la palabra. Lengua y escritura no son sin la materialidad de la corporalidad, que permite que la palabra pase por la boca y la escritura por la mano. El animal es, entonces, el subjectil del discurso y de la escritura". Sin ese intersticio de la impersonalidad animal (el "qué"), no sería posible la constitución de un sujeto humano (el "quién"). De esa manera, lo humano está siempre ya trazado y atravesado por algo que excede al hombre, por su otro y su muerte; está acechado por su propia materialidad animal, por aquello que introduce la ilegibilidad y la dislocación en el seno del ipse, es decir, de lo supuestamente transparente y presente a sí mismo.
} 


\section{El animal, el fármaco y la autodeconstrucción del libro}

humana del libro, y por lo tanto su autoridad como medio eminente de la transmisión de la presencia de la verdad. Pero en cuanto que le insufla vida, la ilegibilidad resulta también constitutiva del libro: "anterior al libro (en sentido no cronológico), aquella ilegibilidad es, pues, la posibilidad misma del libro." (Derrida, 1989: 105). Sin la duplicación del significante y la diseminación irresumible que ella introduce, el espacio de la presencia del significado (el libro) colapsaría. La ilegibilidad animal es entonces a una vez la muerte y la vida del libro. Así, localizada todavía en el libro, pero ya fuera de él, esta ilegibilidad es la de aquella escritura que, según observa Derrida (1997: 83) en el prefacio de la Diseminación, "se apoya en el corte [tranche] del libro cerrado". ${ }^{14}$

La animalidad es entonces el intersticio ilegible que excede al libro, pero que también lo constituye duplicándolo, como el significante al significado. Es el punto donde el libro se excede a sí mismo, aquello que simultáneamente lo hace posible e imposible: el emisario espectral de lo que en La gramatología Derrida llama "texto", "archi-escritura" o différance. ${ }^{15}$ Si no perdemos de vista el hecho de que el libro y el hombre se implican mutuamente, veremos que lo animal traza efectivamente un límite del hombre, pero un límite que atraviesa lo humano mismo y, siguiendo la lógica del fármaco, lo escinde de sí, introduciendo en el hombre lo otro del hombre. ${ }^{16}$

\footnotetext{
14 Nos alejamos aquí de la traducción de Arancibia, quien vierte tranche por "encuadernación". La tranche del libro es en realidad el corte, es decir, el borde de las hojas opuesto al lomo, y que ofrece una superficie sobre la que es posible escribir al cerrar el libro.

15 Sobre la vinculación de las nociones de archi-escritura o texto con el animal, cf. Vitale $(2018,2014)$, para quien "debemos admitir que lo viviente se estructura como un sistema de archi-escritura, [...] un tejido de huellas, es decir, como un texto" (2014: 110). Así, al resaltar el animal en el libro intentamos inscribirnos en aquella tarea que, según Derrida (1986: 25), "desnuda la superficie del texto". Que ésta es una tarea de animalización puede deducirse también del seminario La vie la mort, donde Derrida (2019: 107) señala que extender la noción de texto a la vida biológica no reduce todo "al interior sellado de un libro [...] sino que conduce a una reinterpretación violentísima del límite entre ese interior y su afuera".

16 La relación entre lo humano y lo animal, como la describimos aquí, presenta un paralelismo en la relación entre el yo y el ello, como la describió Freud, desde luego, pero también como ya Nietzsche (2012: 38) la anticipaba al suplantar el "yo pienso" cartesiano por un "ello piensa". El espacio supuestamente transparente del pensar está entonces constituido por "un lugar de opacidad resistente a los intentos de conocimiento cierto y seguro" (Cragnolini, 2019: 59). Siguiendo a Nietzsche y Derrida, Cragnolini ha establecido esta conexión entre el ello y lo animal, presentándolo como el espacio en que el hombre se excede a sí mismo: en los términos del Zaratustra, el cuerpo-animal es el espacio inconsciente de un Selbst del que el hombre es apenas el Ich consciente, y donde éste tiene un lugar meramente funcional en una economía que lo excede. Nuevamente, se trata del intersticio o subjectil impersonal, donde el "quién" deviene un "qué", y donde el yo, el humano, la razón y el sentido
} 


\section{Pedro Tenner}

\section{La gramática agramatical del animal}

Esta relación de duplicación en que se encuentran la legibilidad humana y la ilegibilidad animal puede interpretarse también como una duplicación de lo consciente por lo inconsciente. Tal es la interpretación de lo animal que ha hecho Lippit en su obra Electrical animal, citada más arriba. Esa duplicidad inherente al animal la descubre el autor en su análisis del texto freudiano. En efecto, en Freud,

el descubrimiento del inconsciente en los trastornos histéricos señala la aparición de un mundo otro de la subjetividad: una topología en la que las ideas, los deseos y las pulsiones pueden circular en el mundo sin manifestarse en el lenguaje. Para lo que nos compete, el inconsciente abre dentro de la constitución psico-filosófica un espacio para la entrada de un plexo ideacional anteriormente inadmisible agrupado bajo la figura del animal (Lippit, 2000: 103).

Lo inconsciente no cobra aquí la forma de una región totalmente ajena y separada de la consciencia, sino del doble fantasmático o la "cara oscura" de la consciencia, su punto ciego, acechando, latente, desde sus márgenes. ${ }^{17} \mathrm{~A}$ tal punto es así que las ideas inconscientes -que como vimos cobran para Lippit un carácter animal- se manifiestan como una consciencia suplementaria: "Al atacar, las ideas inconscientes no solo se apoderan del sistema nervioso, sino que también implementan una topografía enteramente otra: no sólo desplazan (y reemplazan) la consciencia, sino que agregan una 'segunda consciencia' en el sistema nervioso" (Lippit, 2000: 106). Sin operar ningún cambio efectivo, duplicando la consciencia o mimetizándose con ella, soldándose a ella, el inconsciente reorienta la topología de la consciencia y del cuerpo. Tal es la reorganización del espacio humano que produce lo animal, alterándolo sin alterarlo, recorriendo los caminos intersticiales de la equivocidad diseminante $y$ estableciendo así conexiones insospechadas, pero ya latentes y constitutivas. Aplicando esta idea al tema de una archi-escritura animal que acecha el libro, podemos

devienen apenas una "estrecha cámara" (Nietzsche, 2011: 156) fundada por lo animal, que a su vez es infundado, sin sentido e ilógico (como veremos en la sección siguiente de nuestro trabajo).

17 Lippit sigue aquí también la interpretación derridiana de Freud, como aparece sobre todo en "Freud y la escena de la escritura". Allí, Derrida se preocupa por demostrar la imposibilidad de una huella inconsciente originaria, previa a -e independiente de- la inscripción consciente. Como ha señalado también Bernet (1993: 157), Derrida "nos invita a no dar por sentada la diferencia entre el inconsciente y la consciencia". 
decir que la animalidad inconsciente de la letra actúa sobre el pensamiento consciente humano de la manera en que Lindberg (2016: 374) ha señalado:

No solo no hay pensamiento sin escritura, sino que además la escritura influye el pensamiento de maneras que éste no puede ver ni controlar. Por ello es que el pensamiento nunca está a salvo de los efectos incontrolables de la escritura.

Este movimiento de reorientación que introduce el inconsciente animal esclarece, en nuestra opinión, una cierta economía oculta que Derrida reconoce en el libro. En efecto, el libro es, como vimos, un afán de totalización: "Todo pasa al libro y en el libro. Todo tiene que habitar el libro" (Derrida, 1989: 103). Pero para hacer posible esa totalización, el libro debe introducir en sí "todas las afirmaciones y todas las negaciones, todas las preguntas contradictorias [...], en una lógica que no se parece a ninguna otra, en la Lógica. Habría que decir aquí la Gramática" (Derrida, 1989: 104). Según Derrida, la gramática del libro deberá ser lo bastante flexible, fluida y agramatical -deberá poder contorsionarse lo suficiente-, como para hacer lugar incluso a la muerte del libro (representada por ejemplo por los ataques deconstructivos de Derrida, inscritos en una sucesión de libros). ${ }^{18}$ Todos los afueras del libro estarán así dentro del libro: "toda esta exterioridad con relación al libro, toda esta negatividad del libro se produce en el libro" (Derrida, 1989: 103). Podríamos decir que el libro sobrevivirá incluso a su muerte: se inmuniza contra ella porque siempre puede anticipársele e incluirla. Efectivamente, Derrida (1989: 106) sostendrá entonces que "las preguntas escritas dirigidas a la literatura, todas las torturas que se le infligen, son siempre transfiguradas, enervadas, olvidadas, por ella y en ella; convertidas en modificaciones de sí, por sí, en sí".

La totalización a la que tiende el libro -su capacidad de absorberlo todo- es entonces posible sólo porque él no es total: porque siempre puede adoptar una nueva forma, reorientarse contorsionarse en una nueva configuración que le permite anticiparse a su muerte e introducirla. Como señala Fóti (1985: 376), para Derrida el libro "se divide o se reduplica inmediatamente: es a una vez una representación, una obra, una totalidad, y sin

\footnotetext{
${ }^{18}$ Esta noción de una agramaticalidad que constituye la gramática en el mismo momento en que la anula es similar a la idea, estudiada por Derrida en su lectura de Bataille, de un sentido sometido a un sin-sentido que lo abarca y que puede suspenderlo en cualquier momento: "el sentido está en función del juego, está inscrito en un lugar dentro de la configuración de un juego que no tiene sentido" (Derrida, 1989: 356). Así, la gramática tendría el lugar del señorío y la agramaticalidad el de la soberanía: esta última "le da a la economía de la razón su elemento, su medio, sus linderos ilimitativos de sinsentido" (Derrida, 1989: 357). Si la comparación que realizamos aquí es correcta, el libro como el espacio racional por excelencia está constituido y horadado por la sinrazón animal soberana. Esta aproximación entre la animalidad y la soberanía la explora Derrida, desde luego, en su seminario La bestia y el soberano.
} 


\section{Pedro Tenner}

embargo también un abismo". Así, esta totalidad no total del libro cobra el aspecto de la estructura descentrada que Derrida (1989: 397) describe en "La estructura, el signo y el juego", donde lo finito y lo infinito difuminan su diferencia:

Si la totalización ya no tiene entonces sentido, no es porque la infinitud de un campo no pueda cubrirse por medio de una mirada o de un discurso finitos, sino porque la naturaleza del campo excluye la totalización: este campo es, en efecto, el de un juego, es decir, de sustituciones infinitas en la clausura de un conjunto finito. Ese campo tan sólo permite tales sustituciones infinitas porque es finito, es decir, porque [...] le falta algo, a saber, un centro que detenga y funde el juego de las sustituciones. [...] No se puede determinar el centro y agotar la totalización puesto que el signo que reemplaza al centro, que lo suple, que ocupa su lugar en su ausencia, ese signo se añade, viene por añadidura, como suplemento. ${ }^{19}$

Si aplicamos esta estructura al libro, podemos decir que tiene límites (bajo la forma de una falta), pero no tiene fin. Puesto que su centro siempre ha sido suplementario, un centro puede suplantar a otro y producir toda una reorientación del campo, sin que parezca operarse cambio alguno en el libro: este último ya ha sido siempre otro de sí, de manera que su devenir otro es su manera de persistir siendo sí mismo. ${ }^{20}$ La gramática del libro no se diferencia en nada de la agramaticalidad más absurda, pues no hay un centro real que arbitre o regule su juego. Es infinito, sí, pero porque su finitud le concede un carácter amorfo y carente de esencia. Puesto que no tiene entonces forma propia, el libro puede adoptar cualquier forma que garantice su supervivencia: desplaza su centro para poder abarcar sus otros, se invierte y revierte, gira sobre sí mismo como el fármaco amorfo y animal. Así, en el seno del libro espacio eminente de la civilización humana-, encontramos la ambigüedad salvaje y animal del fármaco que, como dijimos, a una vez inaugura la posibilidad de la totalización y la hace imposible. En un momento veremos cómo Derrida describe el libro precisamente en estos

\footnotetext{
${ }^{19}$ En nuestra interpretación de este pasaje seguimos a Gasché (1986). Según este autor, Derrida describe aquí un infinito estructural, que es a una vez finito e infinito, y que "libera la posibilidad del infinito genuino, del sueño de la totalización, como esencialmente limitado por su indeleble referencia al otro [...] rastrea la imposibilidad de totalización última en las mismas condiciones que abren la posibilidad de ella" (Gasché, 1986: 304). Gasché describe entonces, como intentamos hacer nosotros, una totalización posible porque es imposible, y que para posibilitarse se mimetiza con su propia imposibilidad. Cf. también el texto de Vitale (2017), quien retoma la lectura del artículo de Gasché.

${ }^{20}$ Lippit (2000: 104) ha señalado que tanto lo animal como lo inconsciente están constituidos por una coherencia en la contradicción, como la que describimos aquí en el libro. Sin embargo, Lippit supone que ello se debe a la ausencia de la muerte en el campo de lo animal, que permite que todas sus formas estén siempre en acto y por lo tanto puedan pasar la una a la otra sin conflicto; en nuestra opinión, lo inagotable del zoofármaco depende precisamente de la reintroducción de la finitud como falta de centro, al punto de que la diferencia entre lo inmortal y lo mortal queda difuminada.
} 


\section{El animal, el fármaco y la autodeconstrucción del libro}

términos -vinculándolo explícitamente el descentramiento y el animal-, al cerrar La escritura y la diferencia.

Antes de ello, sin embargo, quisiéramos resaltar que ya en esta obra Derrida ilustra la capacidad de auto-reversibilidad literaria vinculándola a lo que luego sería el ejemplo prominente en "La farmacia de Platón", a saber, la relación entre el logos y sus contrarios. Puntualmente, en "Cogito e historia de la locura" aparecerán los conceptos de "complicidad" y "ruptura" que, como vimos, describirían posteriormente la reversibilidad farmacológica:

mediante el elogio de la locura, mediante la complicidad con la locura, [los discursos] se miden con lo más próximo a la locura. Como el lenguaje es la ruptura misma con la locura, estará más de acuerdo con su propia esencia y con su vocación, romperá todavía mejor con la locura, si se mide con ella más libremente y se le aproxima más: hasta no estar ya separado de ella más que por la 'hoja transparente' de que habla Joyce (Derrida, 1989: 77-8). ${ }^{21}$

Lo que nos interesa de este pasaje es que el lugar de esta reversibilidad es, precisamente, un libro: la Historia de la locura, de Foucault. Así Derrida (1989: 78) dirá que se siente "tentado por considerar el libro de Foucault como un potente gesto de protección y de encierro [...] Una recuperación de la negatividad". Es en un libro donde la razón opera este gesto farmacológico y autoinmunitario: repite a la locura contra la locura, se vuelve contra sí misma como su otro.

Si tomamos en cuenta la idea de la reversibilidad según está desarrollada en "La farmacia de Platón", y la relación entre la fármaco-lógica y la zoo-lógica, podemos atisbar el carácter animal detrás de la capacidad literaria de reorganización, reorientación y recuperación de la negatividad. De manera similar al caso de la locura, el libro puede hacer uso de la indeterminación o la inagotabilidad animal en contra de lo animal (es decir, para constituir el espacio de lo humano). Veamos, ahora sí, cómo aparece explícitamente esta reversibilidad del animal literario en La escritura y la diferencia.

\section{La auto-deconstrucción del libro}

Para ello nos remitimos a "Elipsis", el segundo ensayo sobre Jabès, con el que Derrida cierra La escritura y la diferencia. Allí, en un pasaje que establece un vínculo explícito entre el destino de lo humano y el libro, este último aparece duplicado por la animalidad amorfa y descentrada bajo el aspecto del pólipo:

\footnotetext{
${ }^{21}$ La referencia a Joyce remite a una cita que Derrida introduce a manera de exergo, donde Joyce señala que Ulysses se distingue de la locura apenas por una hoja transparente, es decir, de manera farmacológica.
} 
El centro era el nombre de un agujero; y el nombre del hombre, como el de Dios, expresa la fuerza de lo que se ha erigido para realizar ahí obra en forma de libro. El volumen, el rollo de pergamino, tenían que introducirse en el agujero peligroso, penetrar furtivamente en la vivienda amenazadora, mediante un movimiento animal, vivo, silencioso, liso, brillante, deslizante, a la manera de una serpiente o de un pez. Así es el deseo inquieto del libro. Igualmente, tenaz y parasitario, amando y aspirando por mil bocas que dejan mil marcas en nuestra piel, monstruo marino, pólipo (Derrida, 1989: 406). ${ }^{22}$

El libro es entonces una animalidad monstruosa, descentrada y amorfa: es decir, es lo otro de sí. Es la totalidad porque nunca es total, es humano porque es animal, siempre tiene un centro porque está descentrado, es el espacio de lo legible porque es el de lo ilegible, el de la forma porque es amorfo, etc. ${ }^{23}$ El libro es infinito porque siempre logrará contorsionarse para hacer lugar a todos sus afueras, incluso su muerte; siempre podrá extender un nuevo tentáculo o una nueva membrana para anticiparse a su muerte. Sin embargo, puede hacerlo precisamente porque ya está duplicado por su muerte y su finitud animal. Como ya es su otro, el libro puede hacer uso de la "inesencialidad" de su otro para inmunizarse contra su otro, es decir, contra sí mismo. Así, su inmunidad es una autoinmunidad. Como ha señalado Lippit (2000: 134), "la literatura puede verse, en la tradición del unheimlich de Freud y el pharmakon de Derrida, como un ejemplo de 'antiliteratura', una vacuna contra sí misma y la animalidad que alberga."

De allí que, también en "Elipsis", Derrida (1989: 403-4) observe que la tarea de deconstrucción del libro no debe hacer más que repetir el libro:

\footnotetext{
22 Vale observar que esta animalidad monstruosa, proteica y literaria es la precursora de la monstruosidad quimérica del animot, que Derrida describiría treinta años después, en El animal que luego estoy si(gui)endo. En esa obra, Derrida (2008: 65) hablará del animot como "ni una especie, ni un género, ni un individuo: es una irreductible multiplicidad viva de mortales y [...] una especie de híbrido monstruoso. Una quimera que espera que su Belerofonte le dé muerte". El animot es monstruoso precisamente porque no tiene centro ni esencia, porque no es algo que es. Es apenas una apertura amorfa, finita por carecer de centro y que existe siempre ya suplantada por una potencial infinidad de formas. Entendidos así, el libro y el animot se inscriben entre aquellas nociones derridianas que Stiegler (2001: 246-7) ha llamado "cuasi-transcendentales".

${ }^{23}$ El problema del animal como doble monstruoso del hombre lo ha tratado Martell (2015), quien utiliza la imagen elocuente del espejo. Desde luego, el espejo es la metáfora eminente del doble, pues me devuelve una imagen que soy y no soy a la vez. Pero Martell también enfatiza el carácter monstruoso del espejo: un espejo debe ser amorfo para poder recibir en sí todas las formas. Debe ser nada para poder ser todo. Como ya indicamos, esa es también una de las características del animal como doble farmacéutico.
} 
Desde el momento en que el círculo da vueltas, que el volumen se enrolla sobre sí mismo, que el libro se repite, su identidad consigo acoge una imperceptible diferencia, que nos permite salir eficazmente, rigurosamente, es decir, discretamente, de la clausura. Al redoblar la clausura del libro, se la desdobla [...] Esta salida fuera de lo idéntico en lo mismo se mantiene muy ligera, no pesa nada por sí misma, piensa y pesa el libro como tal.

El pasaje de la identidad a la mismidad inscribe el libro en la lógica del fármaco, pues introduce en él la diferencia consigo mismo que la mismidad implica. Así, pensar el libro "como tal" es pensarlo en su autoinmunidad farmacológica, en su estar siempre ya duplicado por su otro. La tarea de la deconstrucción sólo tendrá que aprovechar la reversibilidad farmacológica para repetir el libro contra él mismo, recurriendo a la otredad de sí que el libro ya era (y corriendo inevitablemente el riesgo, como Derrida reitera frecuentemente, de volver a quedar apresada en sus tentáculos). Se tratará del anverso de aquel movimiento mediante el cual el libro repetía la animalidad y recuperaba su negatividad para devenir lo anti-animal o humano. El libro es el veneno y el antídoto del libro, pues sólo puede defenderse de su otro exacerbándolo. En ese sentido, el carácter autoinmunitario del libro puede describirse también como auto-deconstructivo: el libro ya está siempre operando contra sí mismo.

\section{Conclusión}

Nuestra intención a lo largo de este artículo ha sido resaltar el carácter farmacológico y autoinmunitario del libro, descubriendo en el texto de Derrida el doble animal que acecha la transparencia literaria de lo humano. El libro está siempre oscilando entre sí mismo y su doble animal, entre la univocidad consciente y las equivocidades inconscientes, para reconfigurarse preservando una apariencia de identidad a sí. Pensado desde ese ángulo, el movimiento de autoinmunización deviene un movimiento de auto-deconstrucción: intentando cerrarse sobre sí mismo para totalizarse, el libro deviene su otro, se corroe y se imposibilita a sí mismo.

Resulta interesante que en El animal que luego estoy si(gui)endo, al referirse al bestiario socrático que mencionamos en la primera parte, Derrida (2008: 56) lo describe como "el bestiario en el origen de la filosofía", y señala que "no se había 


\section{Pedro Tenner}

impuesto por azar en los aledaños de un pharmakon indecidible". En sintonía con esta idea de Derrida, lo dicho en este artículo permite concluir que, en última instancia, el bestiario no es un género literario entre otros, sino el elemento mismo en que se mueve la literatura (entendida como el ámbito en general del libro e incluyendo, por lo tanto, a la filosofía).

Finalmente, el análisis de este artículo nos ha permitido estudiar mejor el movimiento de la deconstrucción de lo humano, que no debe "atacar" desde fuera, sino aprovechar la muerte animal interior, que a una vez constituye y desintegra. El animal literario es aquella figura desfigurada y difusa en la que el libro y el animal son lo mismo y no lo mismo. Revirtiéndose y girando uno sobre el otro, se resguardan en el otro y por ello mueren resguardándose. Una escritura animal y deconstructiva deberá simplemente saber aprovechar esa auto-deconstrucción en la que el libro ya está inmerso, y dejar entrever la animalidad latente que se asoma entre palabra y palabra desde el blanco de la página. Así, esta suerte de escritura animal se identifica con la escritura a la que Derrida (1989: 379) le concede la "mayor fuerza", es decir, aquella que "en la transgresión más audaz, sigue manteniendo y reconociendo la necesidad del sistema de lo prohibido (saber, ciencia, filosofía, trabajo, historia, etc.). La escritura se traza siempre entre estas dos caras del límite." Esta escritura deberá operar un desplazamiento apenas perceptible, que con absoluta ligereza transfiera el peso hacia la cara animal, sin abandonar la cara humana ni operar ningún cambio "real" ni señalable en la estructura del libro (por lo que inevitablemente siempre correrá el riesgo de jugar el juego del libro en favor del libro). Es decir, deberá recorrer ese intersticio farmacológico y amorfo que une y separa al libro del animal, o a lo humano de sí mismo. 
El animal, el fármaco y la autodeconstrucción del libro

\section{Bibliografía}

Adinolfi, M (2011), “La fine dell'epoca del libro. A partire da Jacques Derrida”, Quaestio, 11, pp. 405-427.

Bass, A. (1984), "The Double Game: An Introduction", en Smith, J. y Kerrigan, W. Taking Changes: Derrida, Psychoanalysis and Literature, Baltimore, Johns Hopkins University Press.

Bernet, R. (1993), "Derrida-Husserl-Freud: The Trace of Transference”, en The Southern Journal of Philosophy, XXXII, suplemento, pp.141-158.

Cragnolini, M. (2002), "Temblores del pensar: Nietzsche, Blanchot, Derrida”, Pensamiento de los confines, 12, pp. 111-119.

Cragnolini, M (2007), Derrida, un pensador del resto, Buenos Aires, La Cebra.

Cragnolini, M. (2016a), Extraños animales, Buenos Aires, Prometeo.

Cragnolini, M. (2016b), "Lupus in fabula o la cola del lobo: el animal en el discurso y la escritura", en Instantes y Azares, 17-18, pp. 185-199.

Cragnolini, M. (2019), "Para una deconstrucción del concepto de conciencia, y del lugar del animal en el psicoanálisis", en Intempestivas, Revista de Filosofía, Psicoanálisis y Cultura, pp. 52-64.

Derrida, J. (1986), De la gramatología [trad. Del Barco y Ceretti], México DF, Siglo Veintiuno.

Derrida, J. (1989), La escritura y la diferencia [trad. Peñalver], Barcelona, Anthropos.

Derrida, J. (1997), La diseminación [trad. Arancibia], Madrid, Editorial Fundamentos.

Derrida, J. (2000), Introducción al origen de la geometría [trad. Cohen], Buenos Aires, Manantial.

Derrida, J. (2008) El animal que luego estoy si(gui)endo [trad. De Peretti y Marciel], Trotta.

Derrida, J. (2019) La vie la mort, Seuil. 


\section{Pedro Tenner}

Fóti, V. (1985), “Repetition/Subversion: Derrida, Jabès, and The Language of

Difference", Soundings: An Interdisciplinary Journal, Vol. 68, n. 3, pp. 372-387.

Gasché, R. (1986), “Nontotalization Without Spuriousness: Hegel and Derrida on the Infinite", Journal of the British Society for Phenomenology, Vol. 17, n. 13, pp. 289-307.

Lindberg, S. (2016), “Derrida's Quasi-Technique”, Research in Phenomenology, 46, pp. 369-389.

Lippit, A. (2000), Electric Animal, Minneapolis, University of Minnesota Press.

Martell, J (2015), "The Animal Mirrors: The Human/Animal Divide in Derrida and Deleuze", Mosaic: a journal for the interdisciplinary study of literature, vol. 48, n. 3, pp. 175-189.

Naas, M. (2010), “Derrida's Flair (For the Animals to Follow...)”, Research in Phenomenology, 40, pp. 219-242.

Nietzsche, F. (1997), Así habló Zaratustra [trad. Sánchez Pascual], Madrid, Alianza.

Nietzsche, F. (2011), La genealogía de la moral [trad. Sánchez Pascual], Madrid, Alianza.

Nietzsche, F. (2012), Más allá del bien y del mal [trad. Sánchez Pascual], Madrid, Alianza.

Stiegler, B. (2001), "Derrida and technology: fidelity at the limits of deconstruction and the prosthesis of faith", en Cohen, T. [ed.], Jacques Derrida and the Humanities, Cambridge, Cambridge University Press.

Vitale, F. (2014), "The Text and the Living: Jacques Derrida between Biology and Deconstruction", The Oxford Literary Review, Vol. 36, n. 1, pp. 95-114.

Vitale, F. (2017), “Finite Infinity: Reading Gasché Reading Derrida Reading Hegel ... 'and so on without an end'", CR: The New Centennial Review, vol. 17, n. 3, pp. 43-61.

Vitale, F. (2018), Biodeconstruction [trad. Serratore], Albany, Suny Press. 